\title{
JOINT FOREST MANAGEMENT: A COPING STRATEGY IN THE LOSING BATTLE OF FOREST MANAGEMENT
}

\author{
Anoja Wickramasinghe \\ Department of Geography \\ University of Peradeniya \\ Peradeniya
}

Forest management has been a problem for many countries. The practical evidence points to the fact that it has been a losing battle, because despite all the measures taken to stop forest degradation and denudation, forests have been depleted. Joint Forest Management is a strategy to bring two parties together, the state sector and the local people. To materialise the system many requisites must be fulfilled. There is a need to integrate different tenurial situations primarily the de jure rights of the state and the de facto rights of the people that have been socially accepted in relation to their territorial occupancy over generation. The integration of traditional practices with technical management systems introduced by the state sector is also required. It also points to broader linkages between forest resource management and the non-forest resource management and livelihood.

The partnership between the well established formal institutions equipped with technical staff and legal provisions and the people whose resources and concerns differ from the state agencies seems to cause problems. Our experience reveals that the state agencies have suffered from their inability to enforce state policies. People also have failed to institutionatise their rights and most of the cultural features and social regulations have already been lost.

The economics of the products that people gather for subsistence and in some cases for the market cannot be taken as stimulations for which people will come forward. The experience regarding Joint Forest Management in India and Nepal for example has revealed that the two parties can be brought together under the strategy. The lack of a people centred approach other than the state controlled mechanism has been found to be a threat to the system therefore this paper argues that for a better future more ground work is needed to see when and where the strategy could be adopted.

Proceedings of the Third Annual Forestry Symposium 1997 of the Department of Forestry and Environmental Science, University of Sri Jayewardenepura, Sri Lanka 